\title{
Extraction Methods of Cyanotoxins Aqueous Media and Sediments
}

\author{
Hala El-Nahhal', Maged Yassin1, Mazan Alzaharna1, Ibrahim El-Nahhal'2, Yasser El-Nahhal ${ }^{*}$ \\ ${ }^{1}$ Faculty of Health Sciences, Islamic University of Gaza, P.O. Box 108, Gaza, Palestine \\ ${ }^{2}$ Université de Toulon, Toulon, France \\ ${ }^{3}$ Department Environment and Earth Science, Faculty Science, Islamic University of Gaza, P.O. Box 108, Gaza, Palestine \\ Email: *y_el_nahhal@hotmail.com
}

How to cite this paper: El-Nahhal, H., Yassin, M., Alzaharna, M., El-Nahhal, I. and El-Nahhal, Y. (2021) Extraction Methods of Cyanotoxins Aqueous Media and Sediments. American Journal of Analytical Chemistry, 12, 311-323.

https://doi.org/10.4236/ajac.2021.129019

Received: August 26, 2021

Accepted: September 19, 2021

Published: September 22, 2021

Copyright $\odot 2021$ by author(s) and Scientific Research Publishing Inc. This work is licensed under the Creative Commons Attribution International License (CC BY 4.0).

http://creativecommons.org/licenses/by/4.0/

(c) (i) Open Access

\begin{abstract}
Cyanotoxins are chemical compounds produced by cyanobacterial mats grown in aquatic ecosystems. These may threaten human health and aquatic organisms. Extraction of these toxins is usually associated with many difficulties due to their concentration in aquatic ecosystems. This study is designed to provide suitable and effective extraction procedures that can effectively extract low concentration cyanotoxin from water and bacterial cells. The methodology is based on collecting raw material of cyanobacterial mats from naturally growing sites such as Wadi Gaza along with 16 liters of aquatic surrounding media. The materials were left in the Lab for $24-48 \mathrm{~h}$ for stabilization of the mats. The floating mats were collected using special funnel and allowed to air drying. The aqueous phase was extracted by liquid/liquid extraction using solvent mixture (hexane + ethylacetate $10 \% \mathrm{w}: \mathrm{w}$ ), and by liquid solid extraction using several types of organoclays complexes. The solid phase was extracted by acetone and ultrasonic device. Results showed some difficulties were associated with liquid/liquid extraction whereas effective and easy extraction procedures were obtained by liquid solid extraction using either organoclay complex or activated charcoal. In contrast combination of both solid materials did not show improvement in the extracted cyanotoxin. Thus we recommend the use of organoclays or activated charcoal separately for extracting cyanotoxin. Further improvement of extraction can be tailored by using a specific organoclay complex that has some similarity in the chemical structure between the pre-adsorbed organic cation to the clay mineral and the chemical structure of cyanotoxin.
\end{abstract}

\section{Keywords}

Cyanobacteria, Cyanotoxins, Extraction, Organoclays 


\section{Introduction}

Cyanotoxins are different types of metabolites produced by cyanobacterial mats growing in naturally occurring ecosystems. These toxins are classified as either exotoxins or endotoxins. For instance, microbial toxins are secreted as soluble proteins and have to interact with a plasma membrane either to permeabilize the cell (pore formation) or to enter the cytoplasm to express their enzymatic activity [1]. Some microbial toxins are extremely toxic, e.g. Botulinum neurotoxin is the most effective toxin.

A previous study demonstrated significant impacts of cyanotoxins on drinking water systems, recreational water, and public health [2]. Moreover, levels of cyanotoxins in drinking water should not exceed $1 \mu \mathrm{g} / \mathrm{L}$ according to WHO standards [3], whereas Environmental Protection Agency recommended an acceptable level is $\leq 0.3 \mu \mathrm{g} / \mathrm{L}$ for children under 6 years of age [4] and $\leq 1.6 \mu \mathrm{g} / \mathrm{L}$ for adults [5]. Due to this big concern, there is a large need to develop an easy, fast economically feasible, and environmentally friendly method to extract low concentrations of cyanotoxins. Cyanotoxins can be extracted from different types of cyanobacteria and their growth media [6]. For instance, LeBlanc et al., [7] used liquid chromatography-high resolution tandem mass spectrometry (LC-HRMS/MS) and ${ }^{1} \mathrm{H}$ and ${ }^{13} \mathrm{C}$ NMR-spectroscopy to isolate and characterize [D-Leu $\left.{ }^{1}\right] \mathrm{MC}-\mathrm{LY}(1)\left([\mathrm{M}+\mathrm{H}]^{+} \mathrm{m} / \mathrm{z}\right.$ 1044.5673, $\left.\Delta 2.0 \mathrm{ppm}\right)$. Their results indicate that [D-Leu ${ }^{1}$-containing MCs may be more common in cyanobacterial blooms than is generally appreciated but are easily overlooked with standard targeted LC-MS/MS screening methods. Several attempts have been made for extraction and re-concentration of toxins. For instance, Haque et al., [8] described the extraction procedure of cyanobacterial. Their extraction procedures included sol$\mathrm{id} /$ phase extraction, microwave treatment, sonication, solvent extraction, pulverization and lyophilization. On the other hand, Bryans et al., [9] described the method used to extract bacterial endotoxins from aqueous media. Their method is based on Limulus Amebocyte Lysate (LAL) assay that has been used to test medical devices for bacterial endotoxins. Additionally, Mashile and Nomngongo [10] used solid phase techniques for extraction and re-concentration of cyanotoxins in environmental samples. They emphasized the sampling methodologies and sample preparation techniques mainly that included solid phase extraction and revealed cost effective and friendly features of their techniques. Furthermore, Chen et al., [11] studied the effectiveness of Ethylenediaminetetraacetic acid, EDTA-sodium pyrophosphate solution for extraction procedure for microcystins in soils and lake sediments. They emphasized the use of EDTA-sodium pyrophosphate solution as an extraction solvent. The used procedure proved to be highly efficient and achieved over 90\% recovery. Zervou et al., [12] investigated the use of SPE-LC-MS/MS method for determination of cyanobacterial toxin. They emphasized the following extraction parameters (cartridge material, initial sample $\mathrm{pH}$, sequence of the cartridges) in the SPE assembly as well as composition and volume of the elution solvent. 
The above-mentioned methods used quite general technique to extract cyanotoxins and were limited to certain type of the toxins. Additionally, the methods did not use activated charcoal, clays and/or organoclays complexes, beside the fact that they did not extract cyanotoxins for cyanobacteria and their growth media. This study was designed to investigate the effectiveness of using activated charcoal, clays and organo-clay complex to extract different types of cyano toxin. The idea behind using activate charcoal for extraction procedure is that it has a large surface area that can accommodate large concentrations of cyanotoxin molecules. On the other, hand the use of clay mineral based on the fact that it has a high adsorption capacity [13] [14] [15] and negatively charge surfaces that can adsorb positively charged cyanotoxin, whereas the use of organoclays based on the fact that it can adsorb highly hydrophobic/aromatic cyanotoxin.

\section{Significance}

Cyanobacteria inhabit a large area in Wadi Gaza, and may create many ecological problems such as secretions of their toxins in the Wadi that can damage the wildlife biota and the toxins can reach the Mediterranean Sea and cause death or toxicity to fish. Furthermore, the toxins may leach down to the groundwater and reach the human being causing serious health effects. Limited investigations were done around the globe in the field of cyanotoxins activity against domestic animals (Rabbit) whereas no investigations were carried out in Gaza. Therefore, this research will generate useful data in the field of cyanotoxins that would be helpful to the scientists around the world and it will help the decision makers in the field of health and environment.

\section{Materials and Methods}

\subsection{Collection of Cyanobacterial Mats}

Cyanobacterial mats along with their aqueous media were collected from Wadi Gaza during march 2019 according to method previously described [16] [17] [18] [19]. The samples were transferred to the laboratory at the Islamic University of Gaza where the temperature was maintained at $22^{\circ} \mathrm{C} \pm 2{ }^{\circ} \mathrm{C}$ during the experimental work in the laboratory. The samples were transferred to a glass aquarium $16 \mathrm{~L}$ capacity and left for 2 days in the laboratory condition to allow the mats to reform again. Then the cyanobacterial mats were collected and transferred to a glass plate and left in the laboratory for air-drying. The air-dried materials were kept in plastic bottles for further analysis. Figure 1 shows the collection procedure of cyanobacterial mats and their growth media from Wadi Gaza. Moreover, detailed collection procedure is indicated by different letter in photos.

\subsection{Extraction of Cyanotoxins from Media by Activated Charcoal (Adsorption Method)}

The media (one litter cyanobacterial mats growth media) was filtered through 

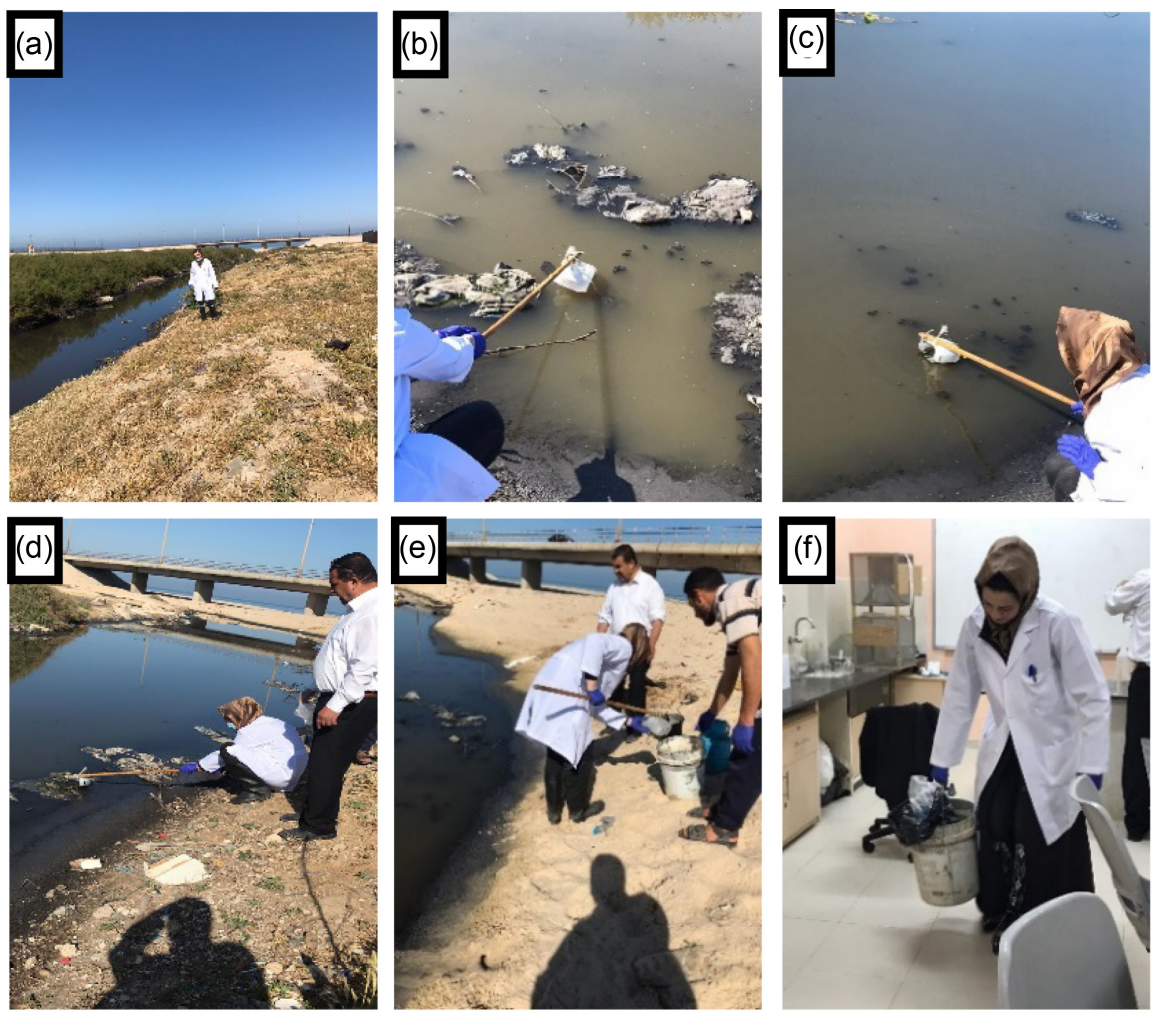

Figure 1. Cyanobacterial mats and growth media collection. (a): Indicates exploring trial of cyanobacterial mat growth community; (b)-(d): show collecting method of cyanobacterial mats and their growth media; (e): shows transferring of collected mats to a plastic container 20 liters capacity; and (f): shows transferring the collected mats to the laboratory.

Whatman filter paper to remove suspended particulate matter. Series of two litter capacity $(\mathrm{N}=8)$, quick fit round bottom flask were washed with distilled water and subdivided into 4 groups. Group 1 containing $10 \mathrm{~g}$ of activated charcoal, Group 2 containing $10 \mathrm{~g}$ of clay (bentonite), group 3 containing $10 \mathrm{~g}$ of clayHDTMA complex (Hexadecyltrimethylammonium bromide), and group 4 contained $10 \mathrm{ml}$ (hexane: ethylacetale mixture 9:1). One letter of filtered growth media was added to each flask.

Then the flasks were kept under continuous magnetic stirring for 48 hours. The magnetic stirrers were stopped to allow precipitation charcoal, clay, and clay-HDTMA. Group 4 contents were transferred to a glass cylinder $4 \mathrm{~L}$ capacity. Then the cylinder was left for 2 hours to allow the organic layer to form. Then the organic layer was collected and the organic solvent was removed by gentle reduced pressure using rotary evaporation [20] [21] [22]. The content of each flask was separated by filtration. Each supernatant was re-extracted again by the same materials mentioned above. At the end of the extraction processes, the solid materials were collected separately and allowed to air drying in the lab for 24 hours. Then the collected solid materials were transferred to a glass flask contained $20 \mathrm{ml}$ solvent mixture (hexane: ethylacetale 9:1 v/v) and transferred to ultrasonic device for a period of 15 minutes at high speed. The solvent mixture 
was separated by filtration and the extraction procedure was repeated again with another $10 \mathrm{ml}$ solvent mixture as mentioned above.

The collected solvent mixture was evaporated under gentle reduced pressure to re-concentrate the cyanotoxin to allow the formation of cyanotoxin crystals.

The collected dried sediments (charcoal, clay, and clay-HDTMA) (bout $20 \mathrm{~g}$ ) was transferred to a $100 \mathrm{ml}$ conical flask containing $50 \mathrm{ml}$ absolute methanol and put under sonication at high speed for $15 \mathrm{~min}$. Then the content was filtered and the charcoal was extracted again by the volume and procedure mentioned above. The supernatant was collected and evaporated under reduced gentle pressure using a rotary evaporator up to complete dryness. This allows the formation of crude cyanotoxins crystals. This extraction procedure was repeated using clays and organo-clays to extract the cyanotoxins.

Figure 2 shows the extraction procedure of cyanotoxins from aqueous media (growth media) and bacterial mats (sediment) using different adsorbing materials (solid phase extraction). More detailed steps of extraction methods are denoted by different letters in Figure 2. A, B and Care extraction of cyanotoxin by activated charcoal, clay and Organo-clay HDTMA complex respectively. Photos $\mathrm{D}$ and $\mathrm{E}$ show the separation techniques using centrifugation. Photos $\mathrm{F}$ and $\mathrm{G}$ denote clean growth media after extraction.

\subsection{Extraction of Cyanotoxin from Bacteria}

Floating cyanobacterial mats were collected from the aquarium on the laboratory by filtration using a vacuum pump. The collected cyanobacteria were left on the laboratory at room temperature for air evaporation. Ten grams of air-dried cyanobacteria mat raw materials were transferred to $100 \mathrm{ml}$ distilled water containing $24 \mathrm{~g} \mathrm{NaCl}$. Then, the system was left under contentious magnetic stirring for 48 hour. Then the system transferred to a round bottom flask and kept under ultra-sonication at a high speed for $15 \mathrm{~min}$. Then the supernatant was separated by centrifugation and used to extract cyanotoxin by $10 \mathrm{ml}$ solvent mixture mentioned above. The remaining sediments were collected and re-extracted again using the same procedure mentioned above.

\subsection{Fluorescence Spectroscopy of Cyanotoxins}

Three-dimensional excitation emission matrices 3D EEMs of fluorescence of cyanotoxins were measured using a 1-cm quartz cuvette in Hitachi F-4500 spectrofluorometer with PMT voltage of $700 \mathrm{~V}$ at $25^{\circ} \mathrm{C}$ through excitation wavelengths (Ex) from $200 \mathrm{~nm}$ to $400 \mathrm{~nm}$ at $5 \mathrm{~nm}$-increment and emission wavelengths (Em) from 220 to $420 \mathrm{~nm}$ at $5 \mathrm{~nm}$-intervals with scan speed of 2400 $\mathrm{nm} \cdot \mathrm{min}^{-1}$ as recently described [23] [24] [25]. Slit width of excitation and emission was set at $5 \mathrm{~nm}$. Matlab 2013a software was used to produce the excitation emission matrix fluorescence landscape. Fluorescence of ultrapure Perkin Elmer deionized water cell blank was subtracted from EEMs of cyanotoxins to get rid of Raman and Reyleigh scattering. 

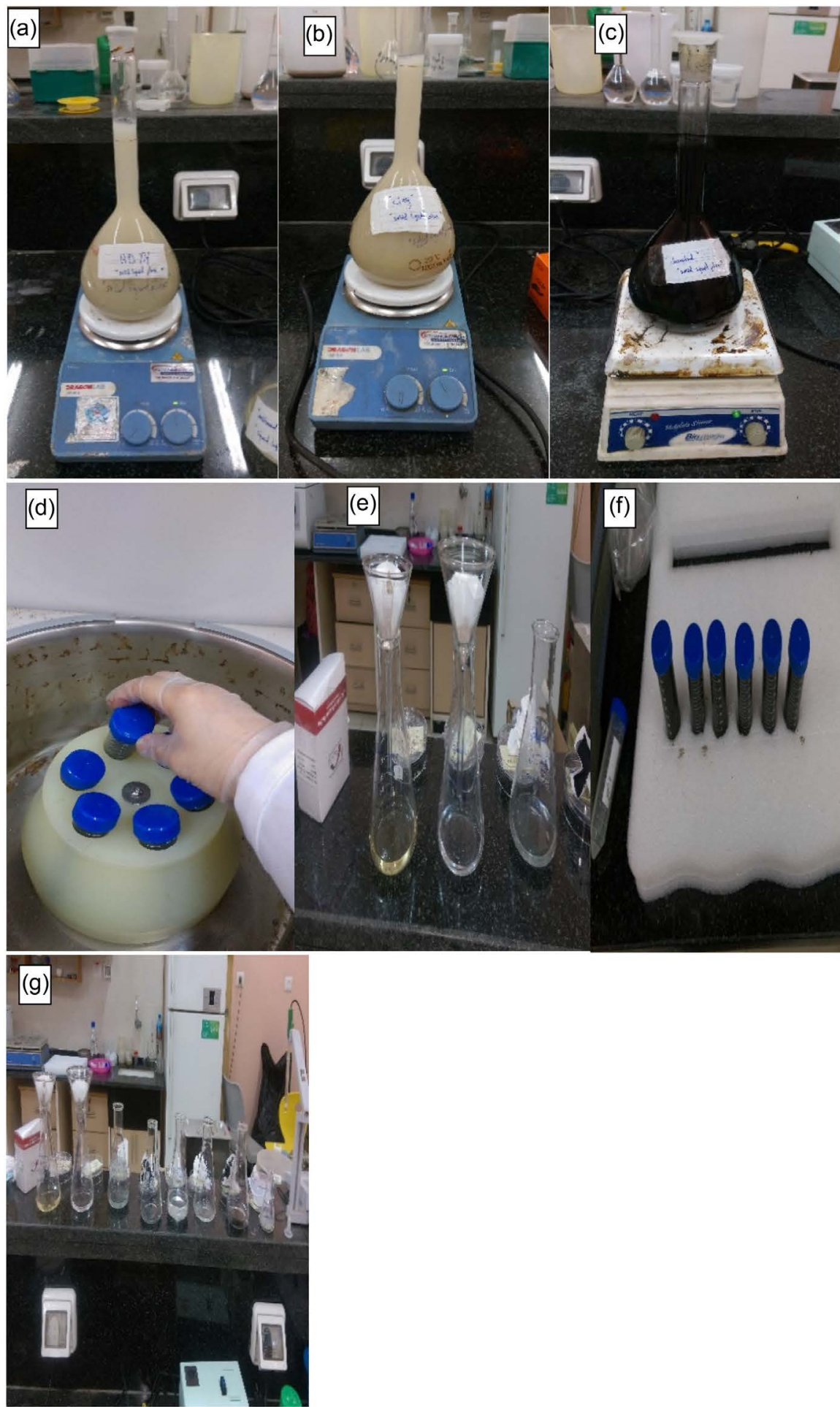

Figure 2. Extraction method of cyanotoxins using different adsorbing materials. (a)-(c): Extraction of cyanotoxin by activated charcoal, clay and organo-clay HDTMA complex respectively; (d)-(e): show the separation techniques using centrifugation; (f)-(g): show clean growth media.

\subsection{Statistical Analysis}

The average weight and standard deviation (SD) of each extraction method was 
calculated and compared to the control group. Moreover, standard error of the mean was calculated $\left(S E=\frac{\sqrt{S D}}{N}\right.$ ) where $N$ is the number of individuals in each treatment, in our case $N=2$. P-value below 0.05 indicates significant differences [26].

\section{Results and Discussion}

\subsection{Collection of Cyanobacterial Mats}

The Photos in Figure 1 clearly demonstrate the steps required to collect cyanobacterial growth media and mats for extraction of cyanotoxin. It is obvious that our team collected the floating cyanobacterial mats and collected water from the surrounding location. The reason behind collecting water (cyanobacterial growth media) for the same location of collecting the cyanobacterial mats is that the concentration of excyanotoxin is nearly high closing to the cluster of cyanobacterial community and tends to decease far away. Additionally, the cluster of cyanobacterial community may have released fresh cyanotoxin that are not exposed to sunlight and undergo photochemical degradation.

\subsection{Extraction of Cyanotoxin}

Moreover, Figure 2 clearly shows four types of extraction procedures so that it would be easy for young scientists and researchers to follow our steps to collect the same results. Meanwhile visualizing the procedure by clear photos makes it easy applicable.

Extracted amounts of cyanotoxins are shown in Figure 3. It is obvious that Liquid/Liquid extracted the lowest amount of cyanotoxin whereas solid liquid

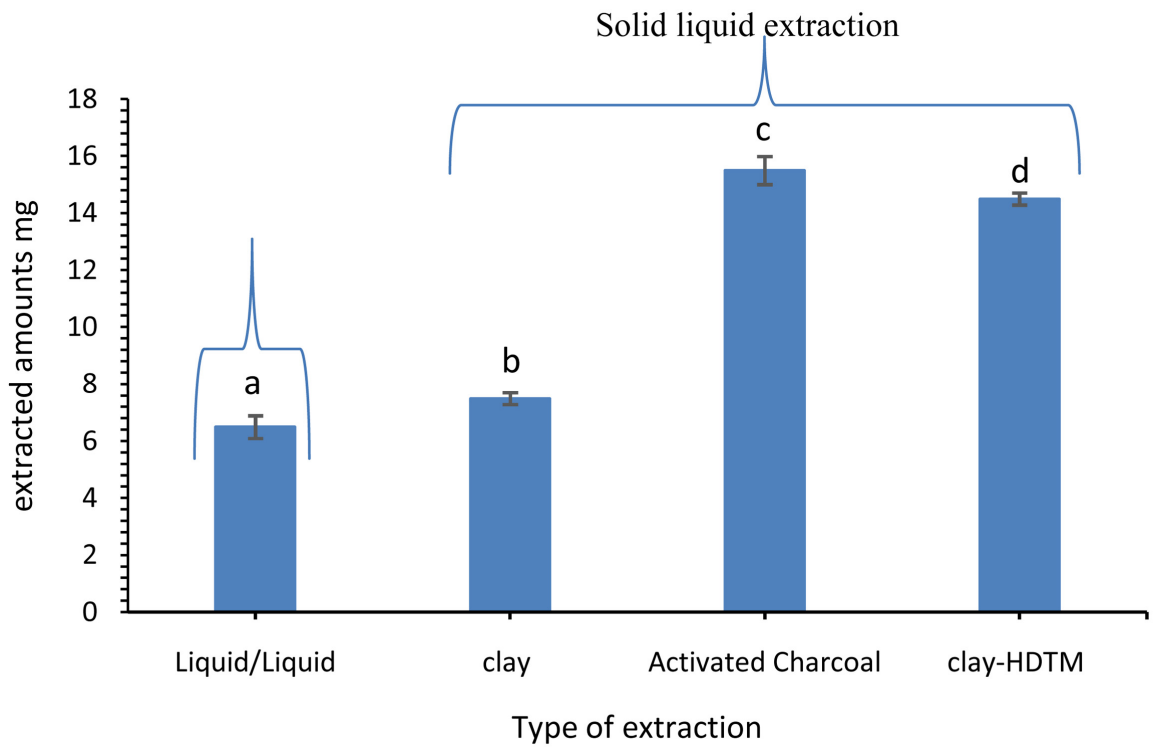

Figure 3. Extraction of cyanotoxin by different methods. Liquid/Liguid, and solid liquid extraction using, clay, activated charcoal and organo-clay (clay-HDTMA). Different letters donate significant differences. 
extraction using clay showed slightly increased extracted amounts. However, using activated charcoal and/or clay-HDTMA extracted two folds of cyanotoxin more than those extracted by clay or liquid/liquid extraction.

The explanation of these results is that Liquid/Liquid extraction procedure use solvent mixture highly hydrophobic which consists of hexane and ethyl acetate at a ratio of 9:1 v/v. Under this condition, cyanotoxin which is an organic compound but not highly hydrophobic. It has a hydrophilic and hydrophobic character that enable the molecule to move through the system. However, using low amount of extraction volume ( $9 \mathrm{ml}$ Hexane $+1 \mathrm{ml}$ ethyl acetate) in 1 letter of growth media of cyanotoxin seems not suitable extraction mixture. It may be better to use solvent mixture contain ( $5 \mathrm{ml}$ Hexane $+5 \mathrm{ml}$ ethyl acetate) than the above mentioned one. This probably is because increasing the volume of ethyl acetate increase the capacity of the mixture to extract more molecules of cyanotoxin. However, for highly hydrophobic molecules such as pesticides, the solvent mixture ( $9 \mathrm{ml}$ hexane $+1 \mathrm{ml}$ ethyl acetate) gave highly extracted amounts from different materials [27]. Meanwhile, the use of clay slightly increased the extracted cyanotoxin, probably due the fact that clay has surface active sites and high adsorption capacity. However, the slightly increased extraction probably because cyanotoxin is a hydrophobic molecules and clay surfaces are hydrophilic and negatively charged. This suggests that only positively charged cyanotoxin such as Lipopolysaccharides and/or cyclic peptides. This phenomenon has previously been observed [28]. Furthermore, changing the clay surfaces from hydrophilic to hydrophobic by pre-adsorbing an organic cation on the surfaces at a certain loadings tremendously increased the extracted cyanotoxin. Additionally, using activated charcoal tremendously increased the extracted amount of toxin due to the surface area, Nano-porous size and hydrophobicity of the surfaces. The explanation of these results is in accordance with the data in Figure 3 and Figure 4.

\subsection{Fluorescence Spectroscopy of Cyanotoxins}

The data in Figure 4 clearly demonstrate the excitation emission matrices measurements of cyanotoxins. It is obvious that two types of cyanotoxin fluorescence have recorded during measurements. One of them has high optical density in the UV-absorption range (Figure 4(a)), namely in the excitation range of 240 $270 \mathrm{~nm}$ (Y-axis) and in the emission wave length range of $340-370 \mathrm{~nm}$ (X-axis). This indicates the presence of aromatic structure of cyanotoxins. On the other hand, Figure 4(b), shows very low intensity of fluorescence in the excitation wavelength range of $280-300 \mathrm{~nm}$ (Y-axis) and in the emission wavelength range of $350-400 \mathrm{~nm}$ (X-axis). This suggests very low concentrations of aromatic structure compounds and suggest the non-aromatic character of the measured cyanotoxins. These observations are in accordance with recent published studies [23] [24] which showed the presence of aromatic compounds in Gapeau river water in France that contain cyanobacteria. Additionally, previous reports. 


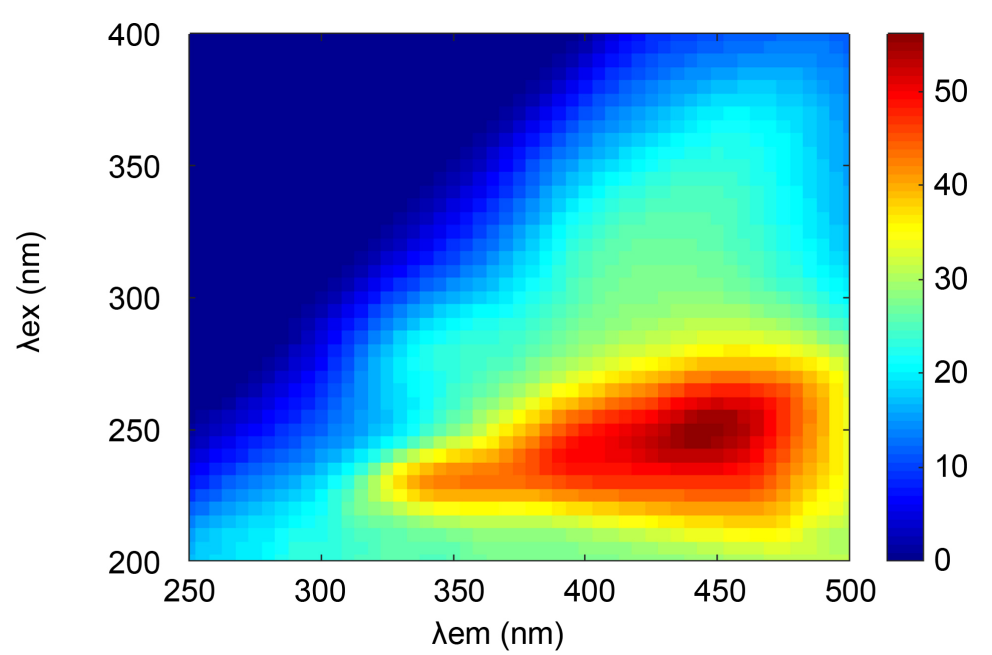

(a)

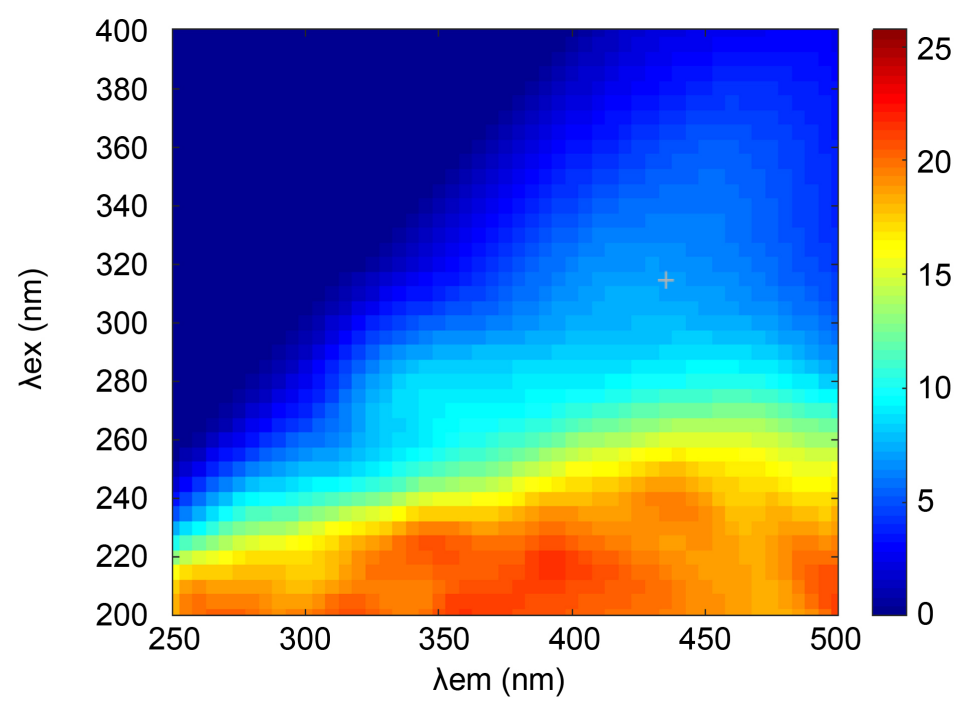

(b)

Figure 4. Excitation emission matrices of cyanotoxin. (a) and (b) represent aromatic like and not aromatic cyanotoxin respectively. Red color represent the optical density of cyanotoxin florescence.

Indicated the presence of alkaloid compounds of cyanotoxin such as Cylindrospermopsin [29], Saxitoxin [30], and Anatoxins [31]. This type of cyanotoxin is nearly aromatic compounds as indicated above by fluorescence emission (Figure 4(a)). In the other hand, the non-aromatic compounds include cyclic hepta-peptides consisting of seven amino acids, such as Microcystin [32], or a cyclic penta peptide such as Nodularin [33], and Lipopolysaccharides [34] [35].

\subsection{Health Relevance of Cyanotoxins}

The health relevance of cyanotoxins emerged from the fact that these compounds are water soluble and have a wide range of $\log \mathrm{P}$ value that enable the toxins to penetrate the biological barriers and accumulate of fat bodies of aquatic organisms. This behavior of cyanotoxin may result in bioaccumulation and 
movement throughout the food chain and cause sever health consequences. This is in accordance with El-Nahhal and El-Nahhal [36] and Ibelings and Chorus [37] who found an accumulation and bioconcentration of cyanotoxin in aquatic organisms. Similarly, previous reports [38] [39] showed various concentrations of cyanotoxins (e.g. saxitoxins and microcystins) in fish samples collected from different lakes having blooms of blue green algae and in water. It has been shown that it caused human health risk to population [40] [41].

\section{Conclusions}

Collection of growth media and cyanobacterial mat for cyanotoxins extraction is a critical point and has a rule in the extracted amount of cyanotoxins. Liquid/Liquid extraction is the fast tool of extraction but it needs further improvement to maximize the extracted toxin.

Activated charcoal and clay-HDTMA tremendously increased the extracted amount of toxin indicating optimal extraction. Excitation emission matrices measurements provide additional scientific evidence of the presence of cyanotoxin.

It can be concluded that using activated charcoal and organoclays are potential candidates for extracting cyanotoxin. Additionally, attention to health safety and personal care measures have to be considered during the extraction and other organoclays complexes can be used during the extraction process.

\section{Acknowledgements}

Prof Dr. Yasser El-Nahhal thanks AvH foundation for funding research stay in Berlin, Germany.

\section{Conflicts of Interest}

The authors declare no conflicts of interest regarding the publication of this paper.

\section{References}

[1] Moura, C.R. (2003) Planar Lipid Bilayers (BLMs) and Their Applications in Membrane Science and Technology. Elsevier, Amsterdam, Vol. 7, 1-1034.

[2] Lee, J., Lee, S. and Jiang, X. (2017) Cyanobacterial Toxins in Freshwater and Food: Important Sources of Exposure to Humans. Annual Review of Food Science and Technology, 8, 281-304. https://doi.org/10.1146/annurev-food-030216-030116

[3] World Health Organization (2011) Guidelines for Drinking-Water Quality. http://apps.who.int/iris/bitstream/10665/44584/1/9789241548151_eng.pdf

[4] US EPA (2015) Drinking Water Health Advisory for the Cyanobacterial Microcystin Toxins.

[5] US EPA (2015) Drinking Water Health Advisory for the Cyanobacterial Toxin Cylindrospermopsin.

[6] Sivonen, K. (2009) Cyanobacterial Toxins. Encyclopedia of Microbiology. Elsevier, Oxford, 290-307. https://www.academia.edu/25481798/Toxic_Cyanobacteria

[7] LeBlanc, P., Merkley, N., Thomas, K., Lewis, N.I., Békri, K., Renaud, S.L., Quilliam, 
M.A., et al. (2020) Isolation and Characterization of [DLeu1] Microcystin-LY from Microcystis aeruginosa CPCC-464. Toxins, 12, 77. https://doi.org/10.3390/toxins12020077

[8] Haque, F., Banayan, S., Yee, J. and Chiang, Y.W. (2017) Extraction and Applications of Cyanotoxins and Other Cyanobacterial Secondary Metabolites. Chemosphere, 183, 164-175. https://doi.org/10.1016/j.chemosphere.2017.05.106

[9] Bryans, T.D., Braithwaite, C., Broad, J., Cooper, J.F., Darnell, K.R., Hitchins, V.M., Karren, A.J. and Lee, P.S. (2004) Bacterial Endotoxin Testing: A Report on the Methods, Background, Data, and Regulatory History of Extraction Recovery Efficiency. Biomedical Instrumentation \& Technology, 38, 73-78. https://doi.org/10.2345/0899-8205(2004)38[73:BETARO]2.0.CO;2

[10] Mashile, G.P. and Nomngongo, P.N. (2017) Recent Application of Solid Phase Based Techniques for Extraction and Preconcentration of Cyanotoxins in Environmental Matrices. Critical Reviews in Analytical Chemistry, 47, 119-126. https://doi.org/10.1080/10408347.2016.1225255

[11] Chen, W., Li, L., Gan, N. and Song, L. (2006) Optimization of an Effective Extraction Procedure for the Analysis of Microcystins in Soils and Lake Sediments. Environmental Pollution (Barking, Essex: 1987), 143, 241-246.

https://doi.org/10.1016/j.envpol.2005.11.030

[12] Zervou, S.K., Christophoridis, C., Kaloudis, T., Triantis, T.M. and Hiskia, A. (2017) New SPE-LC-MS/MS Method for Simultaneous Determination of Multi-Class Cyanobacterial and Algal Toxins. Journal of Hazardous Materials, 323, 56-66. https://doi.org/10.1016/j.jhazmat.2016.07.020

[13] El-Nahhal, Y., Nir, S., Polubesova, T., Margulies, L. and Rubin, B. (1997) Organo-Clay Formulations of Alachlor: Reduced Leaching and Improved Efficacy. Proceedings of Brighton Crop Protection Conference, Weeds, Vol. 1, 21-26.

[14] El-Nahhal, Y. (2003) Adsorptive Behavior of Acetochlor on Organoclay Complexes. Bulletin of Environmental Contamination and Toxicology, 70, 1104-1111. https://doi.org/10.1007/s00128-003-0096-Z

[15] El-Nahhal, Y., Lagaly, G. and Rabinovitz, O. (2005) Organoclay Formulations of Acetochlor: Effect of High Salt Concentration. Journal of Agricultural and Food Chemistry, 53, 1620-1624. https://doi.org/10.1021/jf040383a

[16] EL-Nahhal, Y. and Alshanti, A. (2015) Toxicity of Single and Mixtures Antibiotics to Cyanobacteria. Environment and Analytical Toxicology, 3, 1-8.

[17] Schecter, A., Papke, O., Isaac, J., Hrimat, N., Neiroukh, F., Safi, J. and El-Nahhal, Y. (1997) 2,3,7,8 Chlorine Substituted Dioxins and Dibenzofuran Congeners in 2,4-D, 2,4,5-T and Pentachlorophenol. Organohalogen Compounds, 32, 51-55.

[18] El-Nahhal, Y., Abadsa, M. and Affifi, S. (2013) Adsorption of Diuron and Linuron in Gaza Soils. American Journal of Analytical Chemistry, 4, 94-99.

https://doi.org/10.4236/ajac.2013.47A013

[19] El-Nahhal, Y. (2003) Adsorption Mechanism of Chloroacetanilide Herbicides to Modified Montmorillonite. Journal of Environmental Science and Health. Part. B, Pesticides, Food Contaminants, and Agricultural Wastes, 38, 591-604. https://doi.org/10.1081/PFC-120023517

[20] El-Nahhal, Y. and Safi, J. (2008) Removal of Pesticide Residues from Water by Organo-Bentonites. Twelfth International Water Technology Conference, Alexandria, Egypt, 1711-1724

[21] Safi, J.M., Yassin, M.M., El-Nahhal, Y.Z., Abed, Y.A., Safi, M.J. and Suleiman, H.D. (2019) Childhood Lead Poisoning in Gaza Strip, the Palestinian Authority. Journal 
of Trace Elements in Medicine and Biology: Organ of the Society for Minerals and Trace Elements (GMS), 54, 118-125. https://doi.org/10.1016/j.jtemb.2019.04.004

[22] El-Nahhal, Y., Lubbad, R. and Al-Agha, M.R. (2020) Toxicity Evaluation of Chlorpyrifos and Diuron below Maximum Residue Limits in Rabbits. Toxicology and Environmental Health Sciences, 12, 177-190. https://doi.org/10.1007/s13530-020-00015-Z

[23] El-Nahhal, I., Redon, R., Raynaud, M., El-Nahhal, Y. and Mounier, S. (2020) Characterization of the Fate and Changes of Post-Irradiance Fluorescence Signal of Filtered Anthropogenic Effluent Dissolved Organic Matter from Wastewater Treatment Plant in the Coastal Zone of Gapeau River. Environmental Science and Pollution Research International, 27, 23141-23158. https://doi.org/10.1007/s11356-020-08842-w

[24] El-Nahhal, I., Redon, R., Raynaud, M., El-Nahhal, Y. and Mounier, S. (2021) Modelling of Impact of Presence/Absence of Suspended Particulate Organic Matter from River and Sea and Effluent Wastewater on Fluorescence Signal in the Coastal Area of Gapeau River. Environmental Science and Pollution Research International, 28, 36707-36726. https://doi.org/10.1007/s11356-021-13265-2

[25] EL-Nahhal, I. and El-Nahhal, Y. (2020) Ecological Consequences of COVID-19 Outbreak. Journal of Water Science and Engineering, 1, 1-5.

[26] El-Nahhal, Y. (2020) Pesticide Residues in Honey and Their Potential Reproductive Toxicity. Science of the Total Environment, 741, Article ID: 139953. https://doi.org/10.1016/j.scitotenv.2020.139953

[27] El-Nahhal, Y. (2014) Development of Controlled Release Formulations of Thiabendazole. Journal of Agricultural Chemistry and Environment, 3, 1-8. https://doi.org/10.4236/jacen.2014.31001

[28] El-Nahhal, Y., Wheidi, B. and El-Kurdi, S. (2016) Development of Ecologically Acceptable Chlorpyrifos Formulation for Effective and Safe Application. Journal of Encapsulation and Adsorption Sciences, 6, 91-108. https://doi.org/10.4236/jeas.2016.63008

[29] Bernard, C., Harvey, M., Briand, J.F., Biré, R., Krys, S. and Fontaine, J.J. (2003) Toxicological Comparison of Diverse Cylindrospermopsis raciborskii Strains: Evidence of Liver Damage Caused by a French C. raciborskii Strain. Environmental Toxicology: An International Journal, 18, 176-186.

https://doi.org/10.1002/tox.10112

[30] Froscio, S.M., Humpage, A.R., Burcham, P.C. and Falconer, I.R. (2003) Cylindrospermopsin-Induced Protein Synthesis Inhibition and Its Dissociation from Acute Toxicity in Mouse Hepatocytes. Environmental Toxicology, 18, 243-251.

https://doi.org/10.1002/tox.10121

[31] Mansell, H.L. (1996) Synthetic Approaches to Anatoxin A. Tetrahedron, 52, 6025-6061. https://doi.org/10.1016/0040-4020(95)01076-9

[32] Rao, P.V., Gupta, N., Bhaskar, A.S. and Jayaraj, R. (2002) Toxins and Bioactive Compounds from Cyanobacteria and Their Implications on Human Health. Journal of Environmental Biology, 23, 215-224.

[33] Rinehart, K.L., Harada, K., Namikoshi, M., Chen, C., Harvis, C.A., Munro, M.H., Beasley, V.R., et al. (1988) Nodularin, Microcystin, and the Configuration of Adda. Journal of the American Chemical Society, 110, 8557-8558. https://doi.org/10.1021/ja00233a049

[34] Wiegand, C. and Pflugmacher, S. (2005) Ecotoxicological Effects of Selected Cyanobacterial Secondary Metabolites: A Short Review. Toxicology and Applied Phar- 
macology, 203, 201-218. https://doi.org/10.1016/j.taap.2004.11.002

[35] Stewart, I., Schluter, P.J. and Shaw, G.R. (2006) Cyanobacterial Lipopolysaccharides and Human Health-A Review. Environmental Health, 5, 7.

https://doi.org/10.1186/1476-069X-5-7

[36] El-Nahhal, Y. and El-Nahhal, I. (2021) Cardiotoxicity of Some Pesticides and Their Amelioration. Environmental Science and Pollution Research, 28, 44726-44754.

[37] Ibelings, B.W. and Chorus, I. (2007) Accumulation of Cyanobacterial Toxins in Freshwater "Seafood" and Its Consequences for Public Health: A Review. Environmental Pollution, 150, 177-192. https://doi.org/10.1016/j.envpol.2007.04.012

[38] de Magalhaes, V.F., Soares, R.M. and Azevedo, S.M. (2001) Microcystin Contamination in Fish from the Jacarepagua Lagoon (Rio de Janeiro, Brazil): Ecological Implication and Human Health Risk. Toxicon, 39, 1077-1085. https://doi.org/10.1016/S0041-0101(00)00251-8

[39] Hardy, F.J., Johnson, A., Hamel, K. and Preece, E. (2015) Cyanotoxin Bioaccumulation in Freshwater Fish, Washington State, USA. Environmental Monitoring and Assessment, 187, 1-15. https://doi.org/10.1007/s10661-015-4875-x

[40] Funari, E. and Testai, E. (2008) Human Health Risk Assessment Related to Cyanotoxins Exposure. Critical Reviews in Toxicology, 38, 97-125. https://doi.org/10.1080/10408440701749454

[41] Ghernaout, D. and Elboughdiri, N. (2020) Dealing with Cyanobacteria and Cyanotoxins: Engineering Viewpoints. Open Access Library Journal, 7, e6363. 